\title{
Hypnotic Age Regression and the Occurrence of Transitional Object Relationships
}

\author{
Michael R. Nash, Lynn S. Johnson, and Ronnie D. Tipton \\ University of North Dakota
}

\begin{abstract}
Object relations theory and subsequent empirical investigations have established the characteristic ways in which young children, age 2-6 years, utilize transitional objects (teddy bear, blanket, etc.). Three of these characteristics, spontaneity, specificity, and intensity, were used as the primary criteria to investigate the genuineness of hypnotic age regression when subjects were regressed to age 3 and placed in emotional situations typical of those reported clinically. Two groups of subjects (16 highly susceptible, as "reals," and 15 low susceptible, as simulators) behaved differentially on all three measures, with reals behaving in a generally more childlike manner, thus suggesting an effect attributable to the hypnotic condition. Further, the behavior of these subjects was compared to that of 77 children; reals and children were found to be statistically indistinguishable on the two criteria on which they were compared, but simulators differed significantly from both groups. This pattern of results, along with realsimulator differences, suggests a more complete reproduction of an earlier affective process as a function of meaningful hypnotic age regression.
\end{abstract}

Hypnotic age regression has served as the experimental substrate for a great deal of research concerning the genuineness of hypnotic behavior. Evidence for a genuine revivification process has accumulated from the numerous clinical reports of extraordinary regressions during hypnotherapy (e.g. As, 1962 ; Fromm, 1970). Yet empirical investigations have found no measures on which hypnotically age-regressed behavior reliably transcends waking-state volitional capacity.

Over the past three decades these investigators have focused almost exclusively on two purported characteristics of hypnotic age

We would like to thank Gail Meglitsch and Mark Schuler for their assistance as raters in the Pilot study; Tim Keple and Lynn Eggers who served as project directors; Catherine Sikorsky and Janet Sullivan who helped in the screening; and James Clark and Martin Orne, who suggested elements of our hypothesis and interpretation, respectively. $\mathrm{Fi}$ nally, we thank our experimental subjects who contributed considerable time and emotional energy to our investigation.

Requests for reprints or materials should be sent to Michael Nash, who is now at the Psychology Department, Ohio University, Athens, Ohio 45701. regression : (a) increased recall of remote events and (b) reinstatement of earlier cognitive processes. Although True (1949) and Reiff and Scheerer (1959) claimed dramatic increases in recall for the hypnotically ageregressed condition over waking-state capacity, serious methodological weaknesses have been documented (Barber, 1962; O'Connell, Shor, \& Orne, 1970). Indeed, investigators who have carefully utilized experimenter-blind conditions along with proper motivational control groups have found no evidence for an increase in recall uniquely attributable to hypnotic age regression (Barber, 1961; Cohen, 1972; Leonard, 1965; Wall \& Lieberman, 1976). Similarly, numerous standardized measures have been used to assess possible changes in cognitive functioning: IQ measures (Barber, 1961; Sarbin, 1950), projective tests (Orne, 1951; Schofield, 1974), Piagetian tasks (O'Connell et al., 1970; Reiff \& Scheerer, 1959), and perceptual tasks (Asher, Barber, \& Spanos, 1972; Leibowitz, Graham, \& Parrish, 1972 ; Parrish, Lundy, \& Leibowitz, 1969; Perry \& Chisholm, 1973). Generally, these studies have found that on many mea- 
sures adults who were hypnotically regressed to a specific age responded quite differently than children of that age. For measures on which regressed subjects did elicit childlike responses, waking-state controls performed equally as well. Thus, hypnotic age regression does not appear to facilitate a genuine and unique reinstatement of past cognitive processes or memory components.

On the basis of these laboratory findings concerning cognition and memory, many theorists have concluded that the entire personality of the hypnotically age-regressed subject remains adult. However, clinical reports persist in their observations of convincing revivifications with significant therapeutic implications. Acknowledging this discrepancy, O'Connell et al. (1970) observed:

Age regression, as studied in the laboratory, is rarely accompanied by profound emotional experiences or overt evidence of extreme affect, but revivification in a therapeutic context recaptures experiences that evoke extreme feeling states, almost invariably frightening and extremely unpleasant for the patient. (p. 29, italics added)

If this typically clinical material were meaningfully presented to subjects in the laboratory, it is theoretically possible that any number of subsequent regression phenomena (recovery of memory, return of earlier cognitive processes, reinstatement of old neural mechanisms) might be empirically verified. However, in light of the rather compelling experimental evidence against such phenomena, the present authors posited that it is not cognitive and memory components, but rather earlier affective states, that are primarily reinstated during meaningful hypnotic age-regression experiences. If extremely emotion-laden material could be meaningfully presented to hypnotically age-regressed experimental subjects, a more complete reinstatement of primitive affective processes might occur than is possible during waking state. To test such a hypothesis it was necessary to define experimental procedures and dependent variables that might elicit and assess a previous mode of affective response.

Three developmental measures arising from object relations theory as formulated by D. W. Winnicott provide criteria that are highly relevant to the affective dimension and well suited for group comparison. Winnicott (1953) presented his conception of the mode of object relating in children age 1 to 6 years, introducing the phrase "transitional object" to define the developmental aspects surrounding the child's first treasured possession. Winnicott's article represented the first theoretical synthesis of a commonly observed phenomenon: Infants of both sexes become attached to some external plaything, for example, a teddy bear, blanket, furry animal, soft or hard toy. The first "not me" possession is transitional in two ways, both related to the natural process of decreasing maternal adaptation to the child. First, this possession is transitional in the sense that the teddy bear or blanket is symbolic, representing the love and security of the mother. Second, the transitional object relationship encompasses characteristics of both primitive (hallucination) and developed (reality testing) modes of object relating as the infant strains to adapt to greater increments of frustration. Within this confusing, undifferentiated world of reality and nonreality, inside and outside, the transitional object relationship is the focus of profound affect on the part of the child. Winnicott's theoretical assertions quickly received support from the clinically based literature (Fintzy, 1971; Milner, 1957; Modell, 1968; Munro, 1957; Socarides, 1960; Valkan, 1975). In addition, several empirical investigations proceeded to establish data concerning the dimensions of the transitional object relationship (Busch \& McKnight, 1973; Gaddini \& Gaddini, 1970; Provence \& Ritvo, 1961; Stevenson, 1954).

To further explore the characteristics of the transitional object relationship, Rudhe and Ekecrantz (1974) interviewed 77 mothers of 6-year-old children, obtaining the prevalence, duration, and nature of transitional phenomena. Most of the transitional objects, $89 \%$, appeared by the end of the 2 nd year and enjoyed a mean duration of over 3 years.

Three key observations emerging from the Rudhe and Ekecrantz study and others were utilized by the present investigation:

1. Spontaneity. Winnicott (1953) stated that "the original soft object continues to be absolutely necessary at bedtime or at time of loneliness or when a depressed mood 
threatens" (p. 91). Rudhe and Ekecrantz established that approximately $59.7 \%$ of the children in their study displayed use of transitional objects and that these objects were desired spontaneously at times of stress. Gaddini and Gaddini (1970) found similar results $(59.6 \%)$ in a sample of 40 English and American children living in Rome.

2. Specificity. Winnicott (1953) theorized that the transitional object "must not change unless changed by the infant" (p. 92); it is singular in nature. Rudhe and Ekecrantz reported that $78.3 \%$ of the children having a transitional object displayed rigid and vigorous adherence to this one special object.

3. Affective intensity. "The transitional object is affectionately cuddled as well as excitedly loved and mutilated" (Winnicott, 1953, p. 92). Stevenson (1954), Provence and Ritvo (1961), Busch et al. (1973), and Rudhe and Ekecrantz (1974) all documented the great importance the child attaches to the transitional object, especially during periods of stress or isolation.

These three characteristics of the transitional object relationship, measured in the context of separation anxiety, provide functional criteria against which age-regressed and waking-state behaviors can be compared so as to test two theoretical issues surrounding the impact of meaningful hypnotic age regression: (a) assessment of the hypnotic effect in relation to that of demand characteristics and (b) consideration of a revivification process.

\section{Hypnotic Effect}

This investigation utilized object relations theory, as articulated by Winnicott, to formulate dependent variables that tapped the affective dimension and were hypothesized to yield differences between hypnotic and waking-state response to suggested regression. The authors' assumption was that a previous mode of object relating, that typical of age 3 , would generally involve spontaneous, specific, and intense manifestations of the transitional object relationship when the subject was placed in a stressful situation in which he or she perceived himself to be completely isolated and separate from parents (i.e. experienced separation anxiety). The production of transitional object relationships under hypnotically aroused age regression and task-motivated simulation was examined using the realsimulating model (Orne, 1971). Highly hypnotizable subjects (real group) and lowsusceptible simulating subjects (simulating group) were treated exactly the same, with the exception that the simulating subjects received instructions to respond as if they were highly hypnotizable. If significant group differences arose, the existence of some effect attributable to hypnosis would be suggested.

\section{Consideration of a Revivification Process}

The real-simulating model alone cannot compel the investigator to accept or reject revivification as this factor. The behavior of reals and simulators, therefore, was compared with the behavior of the 77 Rudhe and Ekecrantz (1974) children. If meaningful hypnotic age regression can involve a reinstatement of earlier affective processes, and simulating role play does not, then simulating subjects should have responded in a significantly different manner than the children in Rudhe and Ekecrantz's study; the behavior of real subjects, on the other hand, should closely correspond to that of these same children.

\section{Pilot Study}

A pilot study was undertaken to assess the feasibility of finding group differences on the spontaneity, specificity, and intensity measures, thereby estimating the measurable hypnotic effect. Although the main experiment conformed strictly to the Orne (1971) realsimulating model and its dictate that the hypnotist/experimenter be blind, the pilot study deviated from the model in that the hypnotist/experimenter was aware of group membership. Ten real subjects and 10 simulating subjects were utilized. On all three measures (spontaneity, specificity, and intensity) real-simulator group differences were marginally significant to significant, with the real group being more spontaneous, specific, and intense in their transitional object relationships. 


\section{Method}

The authors felt justified, therefore, in initiating a more rigorously controlled study designed to compare reals and simulators under experimenter-blind conditions. It was expected that the real-simulator differences of the pilot study would surface again. Second, elimination of possible experimenter bias would enable subject data to be compared more confidently with the data derived from the Rudhe and Ekecrantz (1974) study of children. If differences between reals and simulators persisted under blind conditions, the existence of a measurable hypnotic effect would be demonstrated. The nature of this factor and the extent to which it conforms to a revivification process could then be assessed via comparison of reals and simulators to children on the spontaneity and specificity variables.

\section{Subjects}

The 16 subjects selected for the real group scored a mean of 11.1 on the Harvard Group Scale of Hypnotic Susceptibility, Form A (HGSHS-A; Shor \& Orne, 1962) and 23.2 on a modified version of the Stanford Profile Scales of Hypnotic Susceptibility (Weitzenhoffer \& Hilgard, 1967). Subjects assigned to the simulating group scored 3.3 and 3.2 , respectively, on the scales described above. All subjects were university students having no previous experience with hypnosis. The age range was 18 to 24 years $(M=19.8)$. Four male subjects were in each group; the remainder were female. To maintain the blindness of the two hypnotist/experimenters, a project director and a staff member screened and instructed subjects to ensure that each subject was assigned to a hypnotist/experimenter not seen previously.

Treatment of real subjects. Before real subjects were administered the experimental induction and test procedures, they were individually interviewed by the project director for approximately 10 minutes. During this interview the real subject was asked to talk about various aspects of the previous hypnotic screenings. Following this period, the real subject was led to another room in the same building, where the induction was presented and the dependent measure taken by one of the two hypnotist/experimenters.

Treatment of simulating subjects. As was the case with reals, the simulating subjects were individually interviewed by the project director approximately 10 minutes prior to administration of the induction. Unlike the real subjects, however, the simulating subjects were read instructions adapted from Orne (1959). The simulating subjects were informed that in a few minutes they would be working with a hypnotist/ experimenter. The subjects' task would be to convince the hypnotist/experimenter that he was observing an excellent hypnotic subject, a subject capable of entering deep hypnosis with ease. No coaching was given to these subjects as to the kinds of behaviors to elicit. They were told that their success would be related to their intelligent interpretation of the situational cues. ${ }^{1}$

\section{Hypnotic Induction and Age Regression Suggestions}

The entire hypnotic procedure was the same for both simulating and real subjects. The experimenter used an induction adapted from the Stanford Profile Scales of Hypnotic Susceptibility, Form 2 (Weitzenhoffer \& Hilgard, 1967). After the induction, subjects were asked to report their hypnotic depth on a scale from 0 (wide awake) to 10 (very deeply hypnotized). If the subject had not reached a depth of 9 or 10 , suggestions were given that the subject go deeper asleep, until the depth report was significantly increased. At this point, the subject was given suggestions to regress to 3 years of age in a format suggested by Reiff and Scheerer (1959).

\section{Presentation of Stress Situations}

Immediately following the suggestion to become 3 years old, three stressful situations reflecting separation anxiety were presented to the subject. A standardized format of questions designed to assess the extent to which the transitional object relationship was spontaneous, specific, and intense was also presented. The stress situations were (a) alone in bed with everything very quiet and dark (feelings of loneliness and darkness were emphasized); (b) waking up alone in the living room (feelings of isolation, loneliness, and fear were suggested); and (c) mommy returns for a brief time to lay out some toys; soon, however, she leaves again (feelings of intense isolation are suggested, along with a desire "to touch something").

Following each stress situation the subject was asked, "What's happening? What else is happening?", "What are you touching? What else are you touching?", and "What does what you're touching feel like?"

If the criteria for scoring a spontaneous transitional object were not reached by the end of Stress Situations $c$, the subject was told: "You really want to hold something. You really feel so lonely you want to cuddle and hold someting.... What do you want to hold?"

Once an object was spontaneously produced or actively sought, the subject was asked: "Would you like something else with you?", "Anything else?", "What is (transitional object )like?" "Why do you like (transitional object)?", and "What does (transitional object) feel like?"' 2

\section{Criteria for Dependent Measures}

The experimenter considered an object to be a spontaneous transitional object if the subject men-

\footnotetext{
${ }^{1}$ Verbatim instructions to simulators available upon request from the first author.

${ }^{2}$ Complete text of stress situation suggestions available upon request from the first author.
} 
tioned its presence or desired presence in two of the three stress situations. A spontaneous response was scored as 1, and a nonspontaneous response was scored as 0 . For the specificity measure, the number of objects named in response to the question "Would you like anything else?" was recorded. A negative response (specific) was scored as 1 , a positive response of any number was scored as $\mathbf{0}$. Four intensity ratings were obtained for each subject; the hypnotist/experimenter evaluated the intensity manifest in the subject's response to the last three questions on a scale from 1 to 5 . The hypnotist/experimenter also gave a subjective intensity rating from 1 to 5 , low to high, based on general affect and nonverbal behaviors. By testing five subjects preexperimentally, interrater reliability was established at .82. All four intensity measures were summed across questions to give each subject an intensity score with a possible range of 4 to 20 .

\section{Results}

The statistical analysis of the data focused on the two primary issues of this investigation.

\section{Hypnotic Effect}

Significant real-simulator differences occurred on all three dependent measures: spontaneity, specificity, and intensity. As Table 1 indicates, the real group differed significantly from the simulating group in the general direction of conforming to an object relations conception of actual 3-year-old functioning.

Spontaneity. Eleven of the 16 members of the real group spontaneously produced transitional objects $(M=.69)$, whereas only 4 of the 15 simulators were spontaneous $(M=.27)$, $i(29)=2.50, p<.05$.

Specificity. Twelve members of the real group requested just one object $(M=.75)$, whereas six members of the simulating group elicited this specificity $(M=.41), t(29)=2.04$, $p<.05$. Hypnotized age-regressed subjects displayed a transitional object relationship of a significantly more focused nature.

Intensity. The mean intensity rating for the hypnotized group was 13.50, compared to the simulator mean of $7.53, t(29)=4.22$, $p<.0005$.

In summary, on three measures of child object relating, the behavior of highly hypnotizable adults, age regressed to 3 years of age and placed in meaningfully stressful situations, differed significantly from low hypnotizable simulating subjects. These findings further verify the differences found in the preliminary study and consequently support the hypothesis that some factor beyond demand characteristics contributes to the behavior of the hypnotically age-regressed subjects.

\section{Comparison of Group Responses With Normative Data on Children}

If, as the above significant differences suggest, the behavior of the highly susceptible, age-regressed subjects is mediated by some hypnotic effect not present in the wakingstate simulating condition, then the extent to which this effect conforms to a revivification paradigm can be assessed by comparing the Rudhe and Ekecrantz (1974) data on children with responses of the real group and the simulating group.

The rationale for these comparisons across studies is straightforward. In the present study, classification of an object as a spontaneous transitional object hinges on the subject expressing a desire for the same object in two stress situations. Similarly, Rudhe and Ekecrantz (1974) relied on the mother's report of the child's "emotional dependence on a special object which has a soothing and/or comforting effect primarily

Table 1

Two-Tailed $\mathrm{t}$ Tests on Three Dependent Variables

\begin{tabular}{lcccccc}
\hline Variable & $\begin{array}{c}M \\
\text { real } \\
(n=16)\end{array}$ & $\begin{array}{c}M \\
\text { simulation } \\
(n=15)\end{array}$ & $\begin{array}{c}M \\
\text { difference }\end{array}$ & $t$ & $d f$ & $p<$ \\
\hline Spontaneity & .69 & .27 & .42 & 2.50 & 29 & .05 \\
Specificity & .75 & .40 & .35 & 2.04 & 29 & .05 \\
Intensity & 13.50 & 7.53 & 5.97 & 4.22 & 29 & .0005 \\
\hline
\end{tabular}


Table 2

Mean Values of Dependent Measures Obtained From Real and Simulating Adults and Actual Children Age 1 to 6 years

\begin{tabular}{lcccc}
\hline $\begin{array}{c}\text { Subject } \\
\text { group }\end{array}$ & $n$ & $\begin{array}{c}\text { Sponta- } \\
\text { neity }\end{array}$ & $\begin{array}{c}\text { Speci- } \\
\text { ficity }\end{array}$ & $\begin{array}{c}\text { Inten- } \\
\text { sity }\end{array}$ \\
\hline Reals & 16 & .687 & .750 & 13.50 \\
Simulators & 15 & .267 & .400 & 7.53 \\
Children & 77 & .597 & .783 & - \\
\hline
\end{tabular}

B Rudhe and Ekecrantz (1974).

at bedtime and at times of anxiety, illness, etc." (p. 382). A specific response was classified as such if the subject desired only one object in the stress situation. Likewise, Rudhe and Ekecrantz simply recorded transitional phenomena which involved one object (specific) or more than one object (multiple).

Table 2 reports the obtained means on the three dependent measures utilized in the present study, along with the means obtained from the Rudhe and Ekecrantz study of 77 children, age 1 to 6 years. Because spontaneity and specificity are dichotomous variables, the means can also be read as group percentages. Figure 1 illustrates the relationship of real, simulating, and child group data on these two variables.

The behavior of simulators was significantly different from that of children and reals on both spontaneity and specificity measures, whereas differences between the behavior of children and reals were not significant. All differences are summarized in Table 3.

Spontaneity. Of the real and simulating subjects, $68.7 \%$ and $26.7 \%$, respectively, spontaneously produced a transitional object

Table 3

Differences Between Group Means on Spontaneity, Specificity, and Intensity Measures

\begin{tabular}{lccc}
\hline \multicolumn{1}{c}{ Measure } & $\begin{array}{c}\text { Real- } \\
\text { Simulation }\end{array}$ & $\begin{array}{c}\text { Real- } \\
\text { Child }\end{array}$ & $\begin{array}{c}\text { Child- } \\
\text { Simulation }\end{array}$ \\
\hline Spontaneity &. $\mathbf{4 2 *}$ & .09 & $.33^{*}$ \\
Specificity & $.35^{*}$ & -.03 & $.383^{* *}$ \\
Intensity & $5.97^{* *}$ & - & - \\
\hline
\end{tabular}

${ }^{*} p<.05 . \quad * * p<.01$ relationship; this compares to the Rudhe and Ekecrantz observation that $59.7 \%$ of the 77 children were reported by their mothers to have a transitional object. Group means were compared: Simulators differed significantly from children, $t(90)=2.40, p<.05$, as well as from reals. Reals and children did not differ significantly, $t(91)=.667, p=.334$. Thus, the simulating group produced significantly fewer appearances of transitional phenomena than both children and reals.

Specificity. After the transitional object emerged, whether spontaneously or in response to direct suggestion, $75.0 \%$ and $40.0 \%$ of the real and simulating subjects, respectively, desired only the original transitional object. Rudhe and Ekecrantz reported that of children assessed to have transitional objects, $78.3 \%$ desired only the one special object during times of stress. Here again, simulators differed significantly from children, $t(90)$ $=3.11, p<.01$, and they differed significantly from reals, eliciting fewer singular responses than both groups. The difference between children and reals was nonsignificant, $t(91)=.252, p=.748$.

Types of transitional objects. Because there is no accepted or defined typology of transitional objects, it is difficult to confidently compare the qualitative responses of reals and children. To confuse matters further, the

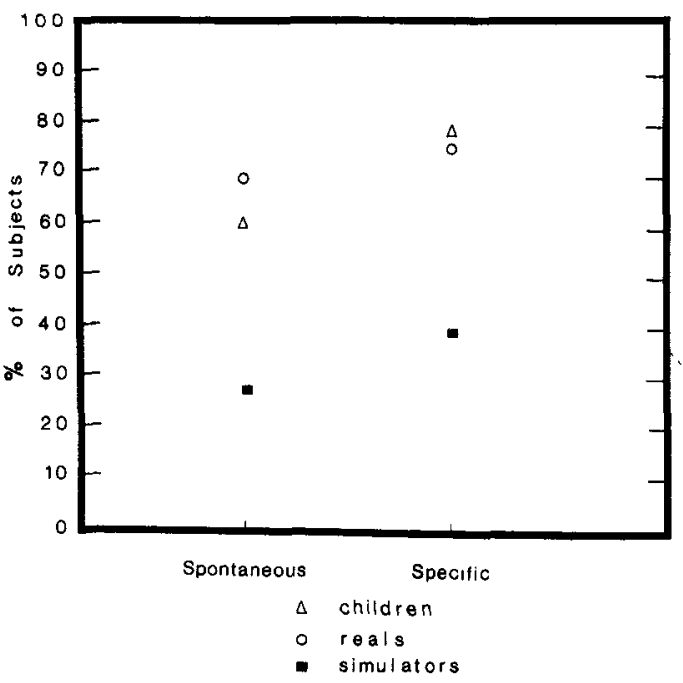

Figure 1. Performance of children, reals, and simulators on the spontaneity and specificity measures. 
responses of reals were often garbled and unclear, rendering precise categorization difficult. Table 4, however, presents the 11 spontaneous responses of reals as they could best be determined by the experimenters. These results conform roughly to the field observations by Rudhe and Ekecrantz (1974) that about half of the specific transitional objects evidenced by children were some sort of cloth, whereas the remainder appeared either to be a toy or to reflect movement toward some other specific object.

\section{Discussion}

\section{Inferring a Hypnotic Effect}

The significant group difference on the spontaneity measure suggests that hypnotized age-regressed subjects are more likely to report a transitional object than their wakingstate, simulating counterparts. Thus, hypnotized age-regressed subjects conform more closely than controls to the object relations prediction that 3-year-olds will have or desire a transitional object during periods of stress. Demand characteristics alone do not produce this childlike spontaneous report. Further, hypnotically age-regressed subjects, when compared to simulators, displayed a transitional object relationship of a more focalized, singular nature, the type of relationship cited by object relations theorists as typical of 3-year-old children. Once again, the behavior of motivated simulators, explicitly instructed to respond to the demand characteristics of the experimental procedure, was significantly different than the behavior of hypnotized subjects. Finally, members of the hypnotized group elicited a significantly more intense relationship with the transitional phenomenon. Responding only to the demand characteristics of the procedure, controls could not simulate the behavior of reals.

On all three measures, motivated subjects behaving on the basis of demand characteristics alone elicited responses quite different from responses of subjects assumed to be hypnotized. The demand characteristics of the hypnotic/experimental procedure were not sufficient to produce in simulators the childlike affect evidenced in hypnotically ageregressed subjects. The data compel the
Table 4

Transitional Objects Produced by Spontaneous and Specific Real Subjects

\begin{tabular}{|c|c|c|}
\hline $\begin{array}{l}\text { Real } \\
\text { subject } \\
\text { no. }\end{array}$ & $\begin{array}{c}\text { Transitional } \\
\text { object }\end{array}$ & $\begin{array}{l}\text { Rudhe/ } \\
\text { Ekecrantz } \\
\text { type }\end{array}$ \\
\hline 1 & Blanket & Cloth \\
\hline 6 & $\begin{array}{l}\text { Part of a } \\
\text { certain shirt }\end{array}$ & Cloth \\
\hline 8 & Blanket & Cloth \\
\hline 10 & Blanket & Cloth \\
\hline 2 & Soft toy ("'Da") & Toy \\
\hline 3 & Toy rabbit & Toy \\
\hline 5 & Doll & Toy \\
\hline 7 & Doll ("Momo") & Toy \\
\hline 12 & Teddy bear & Toy \\
\hline 9 & $\begin{array}{c}\text { Thumb against } \\
\text { some object }\end{array}$ & Uncertain \\
\hline 11 & $\begin{array}{l}\text { Soft ball of } \\
\text { material }\end{array}$ & Uncertain \\
\hline
\end{tabular}

1974.

theoretician to infer some process beyond demand characteristics to explain the responses of the hypnotized subjects.

\section{Consideralion of a Revivification Process}

A literal and comprehensive revivification (Weitzenhoffer, 1957) might be invoked to explain these real-simulator differences. However, in light of the abundance of negative findings concerning reinstatement of cognitive and memory processes, the present authors interpret the results more closely to the data and the measures used: These group differences reflect a more complete reinstatement of a past affective state for subjects experiencing meaningful hypnotic age regression. Such a reinstatement of an affective process would predict the similarity between the object relating of reals and children. In addition, simulators, with less access to the inferred reinstatement, would be expected to produce behavior significantly different from both reals and children. The differences between reals and simulators have been demonstrated and discussed above; differences between these groups and children must now be addressed.

Spontaneity. The probabilities of a real subject and a child eliciting an observable 
transitional object (.687 and .597 , respectively) were statistically indistinguishable, thereby conforming to a reinstatement paradigm of hypnotic age regression. Moreover, the probability of simulators producing transitional objects (.267) was significantly different from both reals and children. Thus, the hypnotized age-regressed subjects evidenced a reinstatement that transcended volitional, waking-state capacities.

Specificity. The Rudhe and Ekecrantz (1974) data on specificity are not as easily compared to the group data from this study. Whereas all adult subjects were tested for specificity whether the appearance of a transitional object was spontaneous or suggested, only children who already were reported by mothers to experience transitional phenomena were included in the Rudhe and Ekecrantz specificity data. For the purposes of this comparison, it is assumed that such specificity is a feature of primitive object relating in general, whether the child possesses a transitional object or not.

For Rudhe and Ekecrantz, $78.3 \%$ of those who possessed a transitional object were specific in their use of it. It is therefore posited that when children who lack an identified transitional object nonetheless seek security through contact with external phenomena, $78.3 \%$ are only content with one such object at a time. Given this extrapolation, the probabilities of a real subject and a child desiring only one object are remarkably close (.750 and .783, respectively) and statistically indistinguishable. Here again the probability of simulators producing a specific response (.40) was significantly different from both children and reals. The real group related to a spontaneously produced or suggested transitional object in ways typical of children, but simulators could not do so. Although the efficacy of inferring an affective reinstatement is suggested by these data, more certain demonstration awaits investigation of the relationship of children to nontransitional, inanimate objects.

Intensity. Rudhe and Ekecrantz (1974) offer no quantitative data on the intensity of the transitional object relationship, but the emotional importance of the transitional object is well documented (Freud \& Burlingham,
1943; Gaddini \& Gaddini, 1970; Rudhe \& Ekecrantz, 1974; Winnicott, 1953). The occurrence of significantly more intense childlike relationships in the real group than in the simulating group is consistent with the evidence supporting a revivification process.

Across two variables, spontaneity and specificity, the behavior of hypnotized age-regressed subjects and children cannot be distinguished, although the behavior of simulators differs from both. In addition, the types of transitional objects presented by real subjects and the concomitant emotional attachment to these objects appear to trace developments in early childhood quite accurately. These results, along with a consistent pattern of real-simulator differences, are predicted by inferring the existence of earlier affective processes operable in the hypnotically ageregressed condition: Real subjects exposed to meaningful and stressful material appear to evidence a more complete and accurate reinstatement of earlier emotional processes. It is possible that the measures used, taken from object relations theory, also tap cognitive and memory processes to some extent. But the authors feel the magnitude of the hypnotic age-regressed effect in this study, and certainly in clinical situations, is due to the extent to which powerful emotive experiences are elicited and measured during the hypnotic procedure.

\section{Conclusions}

This study suggests that a measurable effect of hypnotic age regression will be evidenced in other methodologically sound studies that successfully incorporate some of the important emotional characteristics of clinical hypnosis. Such studies would include (a) a format of suggested situations that has important emotional significance to the subject, (b) a dependent measure that illuminates the capacity of the regressed subject to reexperience earlier affective processess, (c) a measure that reflects the functioning of a broad developmental period (e.g., primitive mode of object relating) rather than the precise behavioral norms of a specific age, and (d) a childlike behavior on the dependent measure that cannot be readily predicted and 
enacted by naive subjects. Although reals may closely approximate the behavior of children on some measures, little is learned about the nature of hypnosis if simulators can do the same.

\section{References}

As, A. The recovery of forgotten language knowledge through hypnotic age regression: A case report. American Journal of Clinical Hypnosis, 1962, 5, 24-29.

Asher, L. M., Barber, T. X., \& Spanos, N. P. Two attempts to replicate the Porrish-Lundy-Leibowitz experiment on hypnotic age regression. American Journal of Clinical Hypnosis, 1972, 14, 178-183.

Barber, T. X. Experimental evidence for a theory of hypnotic behavior: Experimental controls in hypnotic age regression. International Journal of Clinical and Experimental Hypnosis, 1961, 9, 422-443.

Barber, T. X. Hypnotic age regression: A critical review. Psychosomatic Medicine, 1962, 24, 286-299.

Busch, F., \& McKnight, J. Primary transitional objects. The Psychoanalytic Study of the Child, 1973, 12, 193-214.

Cohen, D. I. An experimental investigation of hypnotic hypermnesia. Unpublished doctoral dissertation, University of Kentucky, 1972.

Fintzy, R. T. Vicissitudes of the transitional object in a borderline child. International Journal of Psychoanalysis, 1971, 52, 107-114.

Freud, A., \& Burlingham, P. War and children. New York: International Universities Press, 1943.

Fromm, E. Age regression with unexpected reappearance of a repressed childhood language. International Journal of Clinical and Experimental Hypnosis, 1970, 18, 79-88.

Gaddini, R., \& Gaddini, E. Transitional objects and the process of individuation. Journal of the American Academy of Child Psychiatry, 1970, 9, 479-486.

Leibowitz, H. W., Graham, C., \& Parrish, M. The effect of hypnotic age regression on size constancy. American Journal of Psychology, 1972, 85, 102-121.

Leonard, J. R. Hypnotic age regression: A test of the functional ablation hypothesis. Journal of $A b$ normal Psychology, 1965, 70, 266-269.

Milner, M. The role of illusions in symbolic formation. In M. Klein, T. Heimann, \& R. Money-Kyrle (Eds.), New directions in psychoanalysis. New York: Basic Books, 1957.

Modell, A. Object love and reality. New York: International Universities Press, 1968.

Munro, L. Steps in ego integration observed in play analysis. In M. Klein, T. Heimann, \& R. MoneyKyrle (Eds.), New directions in psychoanalysis, New York: Basic Books, 1957.

O'Connell, D. N., Shor, R. E., \& Orne, M. T. Hypnotic age regression: An empirical and methodological analysis. Journal of Abnormal Psychology Monograph, 1970, 76(3, Pt. 2).
Orne, M. T. The mechanisms of hypnotic age regression: An experimental study. Journal of Abnormal and Social Psychology, 1951, 46, 213-225.

Orne, M. T. The nature of hypnosis: Artifact and essence. Journal of Abnormal and Social Psychology, $1959,58,277-299$.

Orne, M. T. The simulation of hypnosis: Why, how, and what it means. International Journal of Clinical and Experiment Hypnosis, 1971, 19, 183-210.

Parrish, M., Lundy, R. M., \& Leibowitz, H. W. Hypnotic age regression and the magnitudes of the Ponzo and Poggendorff illusions. Journal of $A b$ normal Psychology, 1969, 74, 693-698.

Perry, C., \& Chisholm, W. Hypnotic age regression and the Ponzo and Poggendorff illusions. International Journal of Clinical and Experimental $H_{y p-}$ nosis, 1973, 21, 192-204.

Provence, S., \& Ritvo, S. Effects of deprivation on institutionalized infants. Psychoanalytic Study of the Child, 1961, 16, 189-205.

Reiff, R., \& Scheerer, M. Memory and hypnotic age regression. New York: International Universities Press, 1959.

Rudhe, L., \& Ekecrantz, L. Transitional phenomena, Acta Psychiatrica Scandinavica, 1974, 50, 381-400.

Sarbin, T. R. Mental changes in experimental regression. Journal of Personality, 1950, 19, 221-228.

Schofield, L. Thematic productions under hypnotically aroused conflict in age regressed and waking states using the real-simulator model. Journal of $A b$ normal Psychology, 1974, 83, 130-139.

Shor, R. E., \& Orne, E. C. Harvard Group Scale of Hypnotic Susceptibility, Form A. Palo Alto, Calif.: Consulting Psychologists Press, 1962.

Socarides, C. W. The development of a fetishistic perversion. Journal of the American Psychoanalytic Association, 1960, 8, 281-311.

Stevenson, $\mathrm{O}$. The first treasured possession. Psychoanalytic Study of the Child, 1954, 9, 199-217.

True, R. M. Experimental control in hypnotic age regression phenomena. Science, 1949, 110, 583-584.

Valkan, V. Primitive internalized object relations. New York: International Universities Press, 1975.

Wall, P. D., \& Lieberman, L. R. Effects of task motivation and hypnotic induction and hypermnesia. American Journal of Clinical Hypnosis, 1976, 18, 250-253.

Weitzenhoffer, A. M. General techniques of hypnotism. New York: Grune \& Stratton, 1957.

Weitzenhoffer, A. M., \& Hilgard, E. R. Stanford Profile Scales of Hypnotic Susceptibility. Palo Alto, Calif.: Consulting Psychologists Press, 1967.

Winnicott, D. W. Transitional objects and transitional phenomena: A study of the first not-me possession. International Journal of Psychoanalysis, 1953, 34, 89-97.

Received June 9, 1978

Revision received October 3, 1978 